\title{
ERRO DE INTERPRETAÇÃO SOBRE QUEIXAS ALIMENTARES ASSOCIADO A IDADES PRECOCES DE MANIFESTAÇÃO DA QUEIXA - ESTUDO EM CENTRO DE REFERÊNCIA PARA DIFICULDADES ALIMENTARES
}

Pôster

Autores deste trabalho:

Maria Júlia Russo de Carvalho: Centro de Dificuldades Alimentares - Instituto PENSI

Priscila Maximino: Centro de Dificuldades Alimentares - Instituto PENSI

Raquel Ricci: Centro de Dificuldades Alimentares - Instituto PENSI

Rachel HV Machado: Centro de Dificuldades Alimentares - Instituto PENSI

Cláudia de Cássia Ramos: Centro de Dificuldades Alimentares - Instituto PENSI

Mauro Fisberg: Centro de Dificuldades Alimentares - Instituto PENSI

Área do Trabalho: Nutrição

Data da submissão: $26 / 07 / 2018$ às $20: 37$

\section{Justificativa}

A queixa de dificuldade alimentar (DA) é altamente prevalente na rotina pediátrica, sendo normalmente classificada em apetite limitado, seletividade ou fobia alimentar. Entretanto, algumas queixas podem ser consideradas como interpretação equivocada (IE) por parte dos pais, e a conduta inapropriada dos cuidadores pode gerar consequências deletérias no comportamento alimentar da criança.

\section{Objetivo(s)}

Comparar as características parentais de crianças diagnosticadas com interpretação equivocada em relação a outros tipos de DA.

\section{Método(s)}

Estudo transversal realizado com 159 pares de crianças e seus pais, de ambos os sexos, sendo 23 delas diagnosticadas como 'interpretação equivocada' e 136 como outros tipos de DA. Coletou-se através de prontuário as variáveis IMC dos pais (peso e altura auto- relatados), idade e sexo da criança, antecedente de prematuridade; idade dos pais; paridade da mãe; estilo parental classificado segundo cuidado responsivo e não responsivo; antecedente de doença psiquiátrica e histórico de DA em algum dos pais.

Utilizou-se o teste de regressão logística e teste T-Student, com níveis de significância menor que 5\% e IC95\%, com poder amostral de $94 \%$. A pesquisa foi aprovada por comitê de ética, sob-registro CAAE 32939314.0.0000.5567.

\section{Resultado(s)}

O diagnóstico de IE foi identificado em $14,5 \%$ dos casos analisados. A média de idade das crianças foi de 44,3 meses \pm 31 , sendo a maioria do sexo masculino $(66,7 \%)$. Foi identificado excesso de peso em pelo menos um dos pais em $76,6 \%$ dos casos. Houve associação entre a idade das crianças e o diagnóstico de IE, sendo que as crianças 
com IE apresentaram menor média de idade (dif17, 8meses, IC95\%4.2,31. 4; $p=0,01$ ). Não houve associação entre o tipo de DA e as demais variáveis $(p>0,05)$.

\section{Conclusão (ões)}

Dentre as características avaliadas, a idade foi a única variável associada ao diagnóstico de IE dos pais. Isso reforça a importância da educação precoce nas consultas de rotina com o profissional de saúde. 